ISSN electrónico: 2172-9077

DOI: https://doi.org/10.14201/fjc2016136584

\title{
NuEVO MODELO DE RADIO A TRAVÉS DE LA CUARTA PANTALLA: RADIOVISIÓN, LA RADIO QUE SE VE
}

\section{New Radio Model in the Fourth Screen: Radiovision, The Radio That You Can Watch}

\author{
Sandra CAVIA FRAILE \\ Periodista de La 8 Valladolid, RTVCyL \\ E-mail: sandracavia@hotmail.com \\ (iD http://orcid.org/0000-0002-2469-6108
}

Fecha de recepción del artículo: 30/09/2016

Fecha de aceptación definitiva: 15/10/2016

\section{RESUMEN}

La radio tradicional no es ajena a la revolución social que están suscitando Internet y las nuevas tecnologías. En los últimos años, la cuarta pantalla ha motivado la aparición de nuevos modelos de radio, como es el caso de la Radiovisión. La «radio que se ve» pretende transformar e innovar el medio radiofónico para ofrecer un producto que se ajuste a las exigencias multimedia de los usuarios. Sin embargo, actualmente, la Radiovisión aún se encuentra en una fase inicial y posee muchos aspectos que debe mejorar y cuidar, como los contenidos y la puesta en escena. Todo un desafío para la radio que plantea retos y oportunidades para el periodismo y sus profesionales.

Palabras clave: Radiovisión; radio; cuarta pantalla; Internet; móvil.

\begin{abstract}
The traditional radio is not strange to the social revolution that Internet and new technologies are raising. In recent years, the fourth screen has led the emergence of new models of radio, including Radiovision. The «radio that you can watch» intends to change and innovate the radio broadcasting media to offer a product that meets the multimedia requirements of users. However, currently, the Radiovision is still at an early stage and it has many aspects that it should improve and care, as the contents and the staging. It is a big chance for the radio that poses challenges and opportunities both for journalism and journalists.
\end{abstract}

Key words: Radiovision; radio; fourth screen; Internet, mobile. 


\section{INTRODUCCIÓN}

La radio ha sobrevivido hasta el momento a todas las premoniciones que anunciaban su muerte. Desde el nacimiento de la televisión se anuncia el fin del medio que, durante el siglo XX, reunía a las familias alrededor del transistor y que, hoy en día, acompaña a millones de ciudadanos en su rutina matutina, en su viaje en coche al trabajo o en su momento de ocio cuando juega su equipo favorito.

González Conde (2010) define la radio como una superviviente en su artículo sobre las nuevas alternativas de futuro para este medio:

La radio siempre se ha caracterizado por superar, de forma imaginativa, las situaciones adversas, por lo que no es nuevo que adopte la tecnología emergente y la sepa aprovechar, como así lo hizo desde sus orígenes. (...) Nació como un gran invento de comunicación sin contenidos propios. Se trataba, pues de un maravilloso y mágico aparato de voz y sonidos, que debería rellenarse con una programación adecuada, si quería llegar a convertirse en un verdadero medio de comunicación. Y así lo hizo y llegó a conseguirlo, alcanzando la máxima cuota de audiencia (sobre todo antes de la llegada de la TV) y transformándose en el más poderoso, natural, cercano y creíble (González Conde, 2010, p. 1).

Una definición romántica de los inicios y de los desafíos a los que ha hecho y tendrá que hacer frente la radio. Si la televisión surgió como una amenaza para el transistor, Internet se erige como el punto de inflexión del medio radiofónico que le exige «renovarse o morir».

\section{LA RADIOVISIÓN: ¿NUEVO MODELO RADIOFÓNICO?}

Tras superar la aparición de la televisión y aliarse con Internet, la radio ha podido crear un nuevo modelo gracias a las posibilidades que ofrece la cuarta pantalla. De la concepción multimedia de la ciberradio y las tecnologías podcasting y streaming surge como evolución la Radiovisión ${ }^{1}$.

La primera vez que encontramos el término «Radiovisión» en la literatura científica fue en 1999 en un artículo de Gorka Jakobe Palazio, 'La Radiovisión, el nuevo medio multiservicio' (1999), en la revista 'Zer: Revista de estudios de comunicación'. Por este motivo tomaremos su artículo como antecedente más próximo para este trabajo. Palazio explica en las primeras palabras de este estudio por qué se decanta por este término:

Será «radio» porque tendrá su base en el audio y nos debe recordar sus orígenes; Será «visión» porque con el audio ejercitaremos la vista como complementariedad usual para una información total y porque la radio no va a dejar de renunciar a su cualidad de medio para la información rápida (Palazio, 1999, p. 1).

Para este autor (1999, p. 5), la Radiovisión, «dentro del campo multimedia», ofrece a los usuarios «hiperenlaces, datos, ciber-revistas, imágenes (fotos, gráficos y esquemas), vídeo (ilustraciones, animaciones y vídeo real) e informes multimedia». También «las nuevas aplicaciones y posibilidades multimedia» señaladas por Luis Rodríguez (1997, citado en Palazio, 1999) en una conferencia en 1997 que incluyen «los grupos de discusión por correo, las tertulias en vivo o chats, la radio a la carta, etc.» son

\footnotetext{
${ }^{1}$ A lo largo de todo el estudio se han empleado términos novedosos y no incluidos actualmente en el Diccionario de la Real Academia Española como: radiovisión, radiovisado, radiovidente o radiovisionado, justificados por la necesidad de definir el nuevo concepto de Radiovisión.
} 
considerados como elementos propios de la Radiovisión por Gorka J. Palazio. La mayoría de estos términos, funciones y aplicaciones son conceptos novedosos que surgen gracias a la aparición de la tecnología móvil y la cuarta pantalla.

La radio se compone de cuatro elementos propios: la expresión oral o la palabra, la música, los efectos sonoros y el silencio. Para Pacheco Barrio (2010, p. 3) «comunicar un mensaje radiofónico supone que el emisor ha de representar la realidad en toda su extensión: vista, oído, gusto, olfato y tacto, pero solo se materializan a partir de recursos sonoros». Sin embargo, si la información actual es toda multimedia, como afirma López-Vidales (2011), la radio no puede conformarse ni ser competitiva manteniéndose como medio únicamente auditivo.

Gallego Pérez (2012, p. 3) habla de «la capacidad» de la radio para «compatibilizar otras tareas con su escucha». Esta capacidad es la que permite la aparición de la Radiovisión como un nuevo modelo de medio radiofónico.

La radio no es el único medio que va a evolucionar añadiendo el sentido de la vista a sus tradicionales contenidos emitidos únicamente para el sentido del oído. Ramón Salaverría en una conferencia en la Universidad de Valladolid en mayo de 2016 presentó el término «multisensiorialidad»como característica futura de todos los medios de comunicación. Si actualmente a través de Internet se perciben contenidos con la vista (vídeos), el oído (audios) y, en menor medida, con el tacto (vibración móvil); en el futuro podremos percibir información emitida para los cinco sentidos. Por este motivo, un desarrollo visual de la radio no debe tomarse como exclusivo, sino como parte de la transformación que van aportar las nuevas tecnologías a la forma en la que percibiremos la información en los próximos años.

En este contexto, la Radiovisión se puede considerar como una evolución necesaria de la radio para adaptarse a las nuevas tecnologías emergentes, como la cuarta pantalla, que revolucionarán la comunicación en nuestra sociedad.

\subsection{ANTECEDENTES Y ORÍGENES DE LA RADIOVISIÓN}

Hay tres causas principales que justifican la aparición de la Radiovisión y hacia las que apuntan la mayoría de los autores:

a) Influencia de la televisión.

Pacheco Barrios (2009) considera la influencia de la televisión como uno de razones principales para que las radios desarrollen nuevas fórmulas y evitar así la huida de oyentes.

La televisión puede presumir de ser el medio que más audiencia tiene, con más de 35 millones de telespectadores de los casi 40 millones de ciudadanos que contempla el EGM en su 2. ${ }^{a}$ ola de 2016. Sin embargo, en el caso de la radio, desde finales del siglo XX, comienza a producirse un descenso sostenido su penetración, también según el EGM (Gutiérrez, Ribes y Monclús, 2011).

El consumo de minutos diarios de los medios es otro dato distintivo de la preferencia mediática de los ciudadanos. Mientras que el español medio pasa 228 minutos al día delante del televisor, solo escucha 112 minutos diarios de radio, menos de la mitad (EGM, 2016). Incluso las páginas web de los medios televisivos acumulan una parte importante de las visitas en Internet. Entre los 10 primeros puestos del ranking de las páginas más visitadas por los usuarios se sitúan las webs de Antena3.com (5. $)$, La sexta.com $\left(7 .^{\circ}\right)$ y Rtve.es $\left(10 .^{\circ}\right)$. El visionado de televisión a través de Internet se sitúa en torno al $21 \%$ de los usuarios en los últimos años. Tan solo dos emisoras de radio aparecen en este ranking y lo hacen situadas al final de la clasificación: Europafm.com $\left(19 .^{\circ}\right)$ y Ondacero.es $\left(22 .^{\circ}\right)$. 
Esta última ola publicada por el EGM sitúa a YouTube, página popularmente conocida por ofrecer videos y contenidos audiovisuales, como el sitio web líder en Internet con más de 23 millones de visitas al mes.

También en 2013, el CIS publicaba que más del 56\% de los españoles prefieren la televisión para informarse. A esa inclinación de la población por el medio que ofrece a través de su pantalla audio y vídeo, se suman las cualidades añadidas que ve la población en la televisión: credibilidad, facilidad de acceso, claridad en el tratamiento de la información... Sin embargo, en el mismo barómetro, el medio radiofónico superaba a la televisión en confianza. Pese a la influencia y popularidad de la televisión, la radio es el medio de comunicación en el que más confían los españoles, con una nota de 5,85 sobre 10.

b) Aumento del uso de Internet y tecnología móvil.

En el mundo hay 3.000 millones de usuarios de Internet, sin embargo, hay que considerarlo como una «plataforma occidental» si se atiende a la distribución que tiene el acceso a Internet en nuestro planeta (Salaverría, 2016). La «omniconectividad», conexión en todo momento y lugar, comienza a ser una de las características principales de la sociedad de Occidente, sociedad en la que ya se habla de una generación de nativos digitales marcada por la aparición de Internet, bautizada como $i$ Generation por Bill Gates.

Los jóvenes prefieren Internet como medio de comunicación ante cualquier otro, por lo que los esfuerzos que la radio está realizando con la creación de nuevas fórmulas como la ciberradio o la Radiovisión parecen ir encaminados a atraer la atención de este sector de población que protagonizará el futuro mediático en los próximos años.

En el informe del CIS de marzo de 2016, el 65,1\% de los ciudadanos considera el acceso a Internet como muy necesario y bastante necesario, dato que permite hacerse una idea del alto grado de fidelidad de los usuarios de este medio. Además, cuando se habla de consumo en Internet, no se hace referencia únicamente al ordenador. La era «multipantalla» permite trasladar la escucha de contenidos de audio por Internet a Smartphones, Tablets, iPods... aparatos que eliminan los límites geográficos para el oyente de radio, ventaja conocida y aprovechada por los jóvenes. Según el informe 'La Sociedad de la Información en España', en este año 2016 el móvil y su cuarta pantalla han superado por primera vez al ordenador personal para acceder a Internet.

c) Acercamiento a los jóvenes.

La radio no se ha adaptado a Internet tan rápido como los jóvenes. Pero esto no solo sucede en España, el descenso de la audiencia juvenil de las cadenas radiofónicas es un hecho generalizado en todo Occidente (Gutiérrez, Ribes y Monclús, 2011).

En 2014, el Observatorio de Ocio y el Entretenimiento Digital (OCENDI) llevó a cabo una investigación para conocer los hábitos de escucha de los jóvenes españoles y la valoración que hacían de la radio. Una de las conclusiones que se extrajeron tras encuestar a casi 1.000 estudiantes universitarios se resume en que «los protagonistas del futuro mediático español confirman que la radio no es hoy un medio pensado para ellos» (López, Gómez y Redondo, 2014, p. 61). Este hecho provoca una pérdida de interés evidente por este grupo de población hacia los contenidos radiofónicos.

La recuperación de la audiencia juvenil pasa por responder a las nuevas formas de consumo mediático de este sector de la población (Amoedo, Martínez-Costa y Moreno, 2008, 
citado en Gutiérrez, Ribes y Monclús, 2011). Las emisoras deberán estudiar las preferencias radiofónicas de las nuevas generaciones para adaptar sus contenidos. Además, los jóvenes ofrecen sus propias soluciones cuando son interpelados: incluir una mayor variedad de géneros y emitir seriales divertidos en la radio atraería el interés de la audiencia juvenil (López y Gómez, 2014).

Por el momento, la audiencia dispone de una herramienta muy poderosa para participar activamente en los emergentes modelos de radio. Las redes sociales ya están a disposición de los usuarios para «desarrollar libremente su nuevo rol de generadores de contenidos y contribuir así a la construcción del discurso radiofónico online» (Gutiérrez, Ribes y Monclús, 2015, p. 67).

\subsection{SITUACIÓN ACTUAL Y CONTEXTO DE LA RADIOVISIÓN}

Para compartir, difundir y popularizar los contenidos, las cadenas se sirven como un usuario más de las diferentes redes sociales de Internet, usadas principalmente a través de la cuarta pantalla. En la actualidad, la mayoría de las emisoras se sitúan en Facebook y Twitter por ser las redes sociales más populares. Sin embargo, la popularidad de las redes sociales varía con el tiempo. Es por ello que Cebrián Herreros (2011, p. 20) recomienda a las emisoras «estar muy atentas para mantenerse en las redes que en cada momento sean las de mayor acogida por los usuarios» y así potenciar la influencia y difusión de sus contenidos.

Cebrián Herreros (2008) habla de «radio personal», de «radio grabada-reproducida» o de «radio creada-recreada» por los mismos usuarios al reflexionar sobre lo que las radios tratan de ofrecer actualmente. Tres términos que tratan de poner nombre a una radio que cubra las necesidades personalizadas de cada usuario.

Rodríguez y Peinado (2011, citado en López, Gómez y Redondo, 2014) también aconsejan fomentar la participación activa de los jóvenes y su contribución en la gestión editorial de la información para facilitar la personalización del consumo en radio. Este reto está más cerca de cumplirse gracias a las nuevas características que ha adoptado la radio con Internet: la intemporalidad de sus contenidos, el podcast siempre a disposición del usuario, la interactividad entre internautas... La Radiovisión aparece como solución a esta necesidad ofreciendo un contenido disponible en cualquier momento y que se puede descargar para un consumo offline. Sin embargo, la radio personalizada aún tiene mucho camino por recorrer y nuevos modelos que asimilar para cubrir de forma completa las necesidades de los usuarios.

La audiencia actual está cada vez más definida por «la segmentación, la fragmentación y la especialización» (López y Gómez, 2014, p. 32), características que la radio debería aplicar a su nuevo modelo personalizado con ayuda de las oportunidades que ofrece Internet

En este contexto no se puede obviar un concepto muy ligado a las audiencias juveniles: el 'prosumidor'. La aparición de un consumidor que es, al mismo tiempo, productor de contenidos, se ha bautizado con este nombre y se postula como un oyente o radiovidente preponderante para la industria radiofónica.

Si atendemos a la relación que establecen Ventero y Peña (2011, p. 232) entre la radio y el usuario que participa en el medio: «La radio es el medio más vanguardista y pionero en lo que a participación se refiere, caracterizándose por introducir y comprometer, como ningún otro medio, a sus seguidores, compartiendo con ellos la construcción del discurso radiofónico»; el 'prosumidor' sería la versión 2.0 del oyente que participaba mediante llamadas telefónicas o correos electrónicos y que ahora puede 
incluso colaborar con contenidos multimedia para ayudar a «construir los programas de radio en Internet».

Los 'prosumidores' se convierten así en una fuente de contenidos gratuita e inagotable nada desdeñable para completar la programación de las emisoras. Además, este tipo de contenidos llamaría la atención de la audiencia por su originalidad, singularidad y por la inclusión de los oyentes en el nuevo producto radiovisado.

Este nuevo usuario no pretenderá sustituir de ningún modo la labor profesional del periodista, sumido en la actualidad en un proceso de adaptación sin precedentes. Sin embargo, los usuarios aún «se muestran prudentes a la hora de ejercer su nuevo rol derivado por el contexto digital» (Wardle y William, 2008, citado en Gutiérrez, Ribes y Monclús, 2015, p. 58).

\subsection{TENDENCIAS DE FUTURO Y REALIDAD DE LOS MEDIOS DE COMUNICACIÓN}

La Radiovisión se enfrenta también a una pérdida de identidad con su nueva característica de «radio que se ve» en la cuarta pantalla móvil. La nueva concepción de audio y video aplicada a la radio estrecha la línea que hasta ahora diferenciaba el transistor de la televisión. Para evitar esta confusión en la audiencia, es importante que la radio centre esfuerzos en no perder su identidad pese a incorporar nuevos elementos, algo que no tiene que pasar necesariamente. La radio no es el primer medio de comunicación que se transforma al utilizar Internet como nuevo soporte. Es el caso de los ciberperiódicos o periódicos en Internet, por ejemplo, que también incorporan archivos multimedia, pero no dejan por ello de perder su identidad como medios escritos.

Los distintos medios tradicionales «cada vez se parecen más porque lo que ofrecen es similar, en servicios y en contenidos» (López Vidales, 2011, p. 18). Pero Cebrián Herreros (2007) defiende que mientras el sonido sea el núcleo del medio se puede seguir hablando de radio.

Por el contrario, hay otros autores que instan a «abandonar el concepto tradicional de radio» (Rodero, 2002, citado en López y Gómez, 2014, p. 33) cpmo única vía para innovar y lograr «un producto radiofónico adecuado a Internet».

Frente a esta variedad de opiniones igual de legitimadas, deberán ser los propios medios los que defiendan su diferenciación tradicional mediante nuevas estrategias de comunicación adaptadas.

Si la premisa es innovar, en 2014, López y Gómez, hablaban de poner en marcha «formatos más atrevidos, nuevas voces y nuevas caras». Esta última aportación: «nuevas caras», contempla ya a la Radiovisión como una realidad a tener en cuenta.

\section{JUSTIFICACIÓN DEL ESTUDIO}

El carácter emergente de la Radiovisión en la cuarta pantalla como evolución de la radio tradicional y la ciberradio justifica la importancia de definir este nuevo modelo radiofónico.

Numerosos expertos en radio, ciberradio y nuevas tecnologías han descrito la situación actual que vive el medio radiofónico y el reto que tiene ante sí con la aparición de Internet. Todos ellos han esbozado un contexto social, tecnológico y mediático que ha propiciado la aparición de la Radiovisión, pero sin profundizar en este nuevo modelo, deficiencia que pretende suplir este estudio.

Este trabajo persigue aglutinar las características que muchos expertos han definido como nuevas en la radio que se alía con Internet y que la Radiovisión ha asumido como propias por sus circunstancias y cualidades a través de la cuarta pantalla.

En esta sociedad multimedia, la evolución de un medio auditivo que se transforma y adquiere propiedades visuales conlleva cambios a todos los niveles: desde la aparición de nuevos perfiles profesionales hasta la emersión de una nueva narrativa informativa. 
La Radiovisión y todas las nuevas estrategias informativas en Internet implican también una evolución para el periodismo tradicional. La labor periodística adquiere gracias a la Radiovisión un nuevo modelo de comunicación con características, estructuras, medios, profesionales, narrativas y funciones propias que son necesarias analizar.

\section{Metodología}

Para abordar esta investigación se ha diseñado una metodología que abarca parámetros de índole cualitativa.

La obtención de datos cualitativos se ha llevado a cabo mediante la confección de una ficha de análisis basada en el análisis bibliográfico de informes y estudios precedentes sobre algunas de las cuestiones a investigar. También se han incluido ítems propios motivados por la necesidad de recabar información específica para responder a los objetivos de esta investigación.

\subsection{UNIDADES DE ANÁLISIS}

Para conocer las características actuales de la Radiovisión a través de la cuarta pantalla se ha elegido como estudio de caso el programa 'Hoy por Hoy' de la 'Cadena Ser'. La elección de este programa radiofónico viene justificada por el último EGM (2. ${ }^{a}$ ola 2016) publicado por AIMC.

La 2 a ola del EGM de 2016 sitúa la 'Cadena Ser' (Grupo Prisa) como líder de audiencia de la radio española con más de 4,5 millones de oyentes, esto supone el 18\% de la audiencia total (25 mill.).

Dentro de la 'Cadena Ser', el EGM muestra el programa 'Hoy por Hoy' como el de mayor audiencia de la radio en España. 'Hoy por Hoy', presentado por Pepa Bueno y Gemma Nierga de lunes a viernes, cuenta con más de 3 millones de oyentes en nuestro país, muy por encima del resto de programas radiofónicos. Estos datos de audiencia y el uso del modelo de Radiovisión por parte de 'Cadena Ser' justifican la elección de 'Hoy por Hoy' como unidad de análisis para llevar a cabo esta investigación sobre la Radiovisión en la cuarta pantalla.

Como unidades de análisis, se han elegido cuatro programas de 'Hoy por Hoy' publicados según el modelo de Radiovisión por 'Cadena Ser' en su perfil de YouTube y página web. Estos contenidos se pueden consumir únicamente a través de un teléfono móvil o un ordenador. Todos los programas han sido emitidos entre el mes de enero y el mes de abril de 2016, se ha escogido uno por mes. Las cuatro unidades de análisis seleccionadas aleatoriamente son las siguientes:

1. 15 de enero de 2016: «Malas pintas» por Manuel Jabois. Cadena SER. Recuperado el 10 de abril de 2016 en: https://youtu.be/6Kv4WAWC7XQ

2. 2 de febrero de 2016: Cifuentes: "Que me quiten de la carrera sucesoria». Cadena SER. Recuperado el 10 de abril de 2016 en: https://youtu.be/L1AUr7R7eyY2

3. 14 de marzo de 2016: Thais Villas: «Fui al casting de El Intermedio en katiuskas». Cadena SER. Recuperado el 10 de abril de 2016 en: https://youtu.be/-HjI2JXw5m4

4. 3 de abril de 2016: Albert Rivera: «No vamos a compartir un gobierno a tres». Cadena SER. Recuperado el 10 de abril de 2016 en: https://youtu.be/aAINgdY2ow8

\footnotetext{
2 El apartado de análisis general que incluye los datos propios de 'Hoy por Hoy' ya ha sido desarrollado a lo largo de la metodología para presentar las unidades de análisis seleccionadas y su justificación. Los datos recogidos a partir del segundo apartado del análisis general: «Datos propios del programa a analizar»), varían según la unidad analizada y permiten extraer tendencias o características propias del modelo radiovisivo de 'Hoy por Hoy' en la cuarta pantalla.
} 
'Hoy por Hoy' se emite de lunes a viernes y tiene una duración total de 6 horas y 20 minutos, desde las 6 de la mañana hasta las 12:20 del mediodía.

Desde el año 2013, la 'Cadena Ser' publica en YouTube con audio y vídeo algunos de sus programas más destacados. Concretamente, las secciones más populares de sus colaboradores y entrevistas a personajes conocidos. Estos vídeos únicamente pueden ser visionados en la cuarta pantalla a través de la página web de Cadena Ser y en la plataforma de YouTube, mediante el canal de 'Cadena Ser', en la lista de reproducción de 'Hoy por Hoy'.

Estos vídeos se elaboran a través de 'Ser TV', sección creada por la 'Cadena Ser' para etiquetar y marcar con mosca sus contenidos audiovisuales. Sin embargo, si un oyente quiere ver cómo ha sido grabado un programa en el estudio de radio para observar a sus protagonistas, deberá acudir al canal de YouTube a través de su móvil, donde la búsqueda es mucho más sencilla y los contenidos más específicos.

\subsection{FICHA DE ANÁLISIS}

Para analizar el programa de radio seleccionado para este estudio, el programa 'Hoy por Hoy' de la 'Cadena Ser' emitido en su formato radiovisivo a través de la cuarta pantalla, se han utilizado fichas de análisis de elaboración propia. Las fichas empleadas constan de un análisis de datos generales y otro análisis de características específicas.

En total, 6 apartados desglosados a continuación:

Análisis general:

a) Datos propios de 'Hoy por Hoy': para conocer la cadena de emisión, horario, periodicidad, duración, género radiofónico, porcentaje de audiencia y nombre de los presentadores principales.

b) Datos propios del programa a analizar: para recoger el nombre, enlace de Internet, fecha de emisión, plataforma virtual empleada, duración del vídeo, número de visitas, aceptación de la audiencia («me gusta», «no me gusta»), disponibilidad del vídeo en la web de 'Cadena Ser' y tipo de edición empleada sobre el video original.

Análisis específico sobre el modelo de Radiovisión:

c) Presentadores, invitados y colaboradores.

d) Puesta en escena: para observar, comparar y analizar el escenario, fondos (corporativo, neutro, con público), posición de los protagonistas (de pie, sentados), cuidado de la puesta en escena, iluminación y número de cámaras, así como los rótulos, planos y cabeceras editados tras las grabación. Este apartado ayudará a responder a la primera y segunda hipótesis ( $\mathrm{H} 1$ y H2).

e) Contenido: para recoger el tipo de contenido (entrevista, informativo, opinión o tertulia), tema principal del programa y su novedad en el medio radio, elementos de continuidad empleados, publicidad incluida en el vídeo y apelaciones a los oyentes y a las redes sociales. Este apartado permitirá analizar la tercera hipótesis (H3).

d) Comunicación no verbal: Este apartado ayudará a examinar la primera y la segunda hipótesis (H1 y H2).

Las variables analizadas en esta sección son los siguientes:

- Kinesia: es la disciplina que analiza aspectos de la comunicación no verbal relacionados con la postura, los gestos y el rostro. 
- Paralingüística: esta disciplina analiza la voz, elemento por excelencia del medio radiofónico.

- Proxémica: esta especialidad estudia la distancia correcta entre interlocutores y la distribución del entorno inmediato

- Indumentaria: la vestimenta toma una importancia inédita en la radio gracias al modelo de Radiovisión.

Tabla 1. Ficha de análisis resumida del programa 'Hoy por Hoy': unidades de enero y febrero

\begin{tabular}{|c|c|c|c|}
\hline & & & \\
\hline & \multirow{2}{*}{ NOMBRE } & PROGRAMA ENERO & PROGRAMA FEBRERO \\
\hline & & $\begin{array}{l}\text { 'Malas pintas' por Manuel } \\
\text { Jabois }\end{array}$ & $\begin{array}{c}\text { Cifuentes: "que me quiten de la } \\
\text { carrera sucesoria" }\end{array}$ \\
\hline & FECHA & 15.01 .2016 & 2.02 .2016 \\
\hline & DURACIÓN & 3 & 5' 41" \\
\hline & \multicolumn{3}{|c|}{ PUESTA EN ESCENA } \\
\hline \multicolumn{4}{|l|}{ ESCENARIO } \\
\hline \multicolumn{4}{|l|}{ PUESTA EN ESCENA } \\
\hline & cuidada & & \\
\hline & descuidada & & \\
\hline \multicolumn{4}{|l|}{ FONDO } \\
\hline & corporativo & & \\
\hline & neutro & & \\
\hline \multirow{2}{*}{\multicolumn{4}{|c|}{ ILUMINACIÓN }} \\
\hline & & & \\
\hline & intensa & & \\
\hline & débil & & \\
\hline & cuidada & & \\
\hline & descuidada & & \\
\hline \multicolumn{4}{|l|}{ CABECERA } \\
\hline & inicial & & \\
\hline & final & & \\
\hline \multicolumn{4}{|l|}{ RÓTULOS } \\
\hline & sí & & \\
\hline & no & & \\
\hline \multicolumn{4}{|l|}{ N. ${ }^{\circ}$ CÁMARAS } \\
\hline \multicolumn{4}{|l|}{ IMAGEN PANTALLA } \\
\hline & plano fijo & & \\
\hline & zoom out & & \\
\hline & zoom in & & \\
\hline & Imax. tiembla & & \\
\hline \multicolumn{4}{|l|}{ PLANO EMPLEADO } \\
\hline & general & & \\
\hline & primer plano & & \\
\hline & plano detalle & & \\
\hline & plano lateral & & \\
\hline \multicolumn{4}{|l|}{ CAMBIOS DE PLANO } \\
\hline & sí & & \\
\hline & $\frac{\text { no }}{\text { fundidos }}$ & & \\
\hline & fundidos & & \\
\hline
\end{tabular}




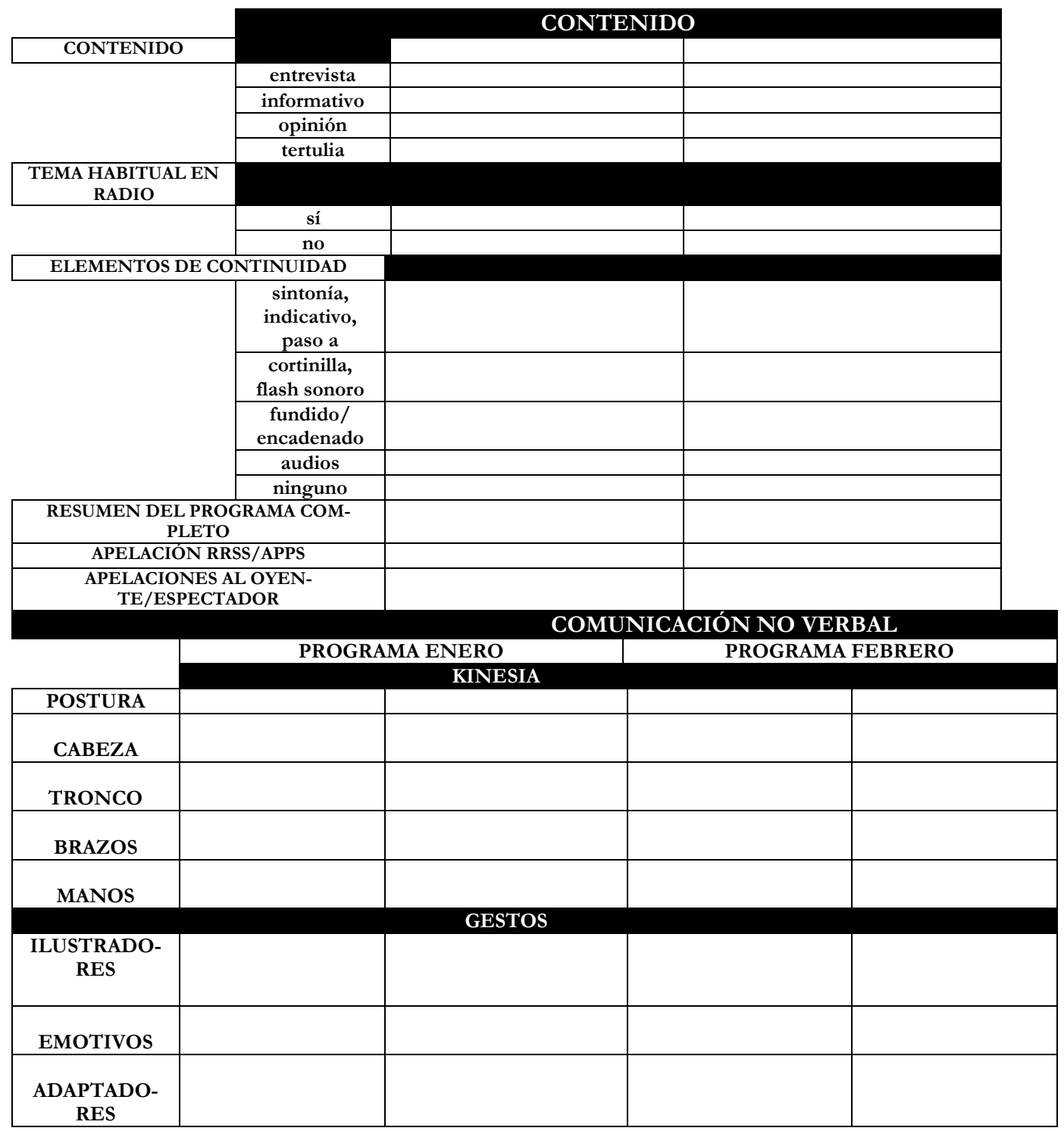

Fuente: Elaboración propia.

\section{RESULTADOS DEL ANÁLISIS SOBRE LAS UNIDADES DE RADIOVISIÓN}

Tras haber examinado las unidades de análisis, se observa que todas ellas están disponibles en la plataforma virtual de YouTube, accesible mediante un móvil. Estos vídeos también se pueden encontrar en la página web de 'Cadena Ser', pero son difíciles de localizar, no hay un buscador especializado que permita acceder a todos los contenidos radiovisados de 'Hoy por Hoy'. Es por ello que YouTube se 
convierte en una herramienta aliada del usuario para acceder de forma sencilla desde su teléfono móvil al contenido que desea consumir.

Todos estos contenidos radiovisados están publicados en YouTube a través del mismo perfil: 'cadenaser (https://www.youtube.com/user/cadenaser)', canal oficial de 'Cadena Ser', y dentro del canal corporativo a través de la lista de reproducción denominada 'Hoy por Hoy'.

\subsection{DATOS PROPIOS DEL PROGRAMA A ANALIZAR}

Después de analizar estas características comunes compartidas por todas las unidades de análisis, aparecen variables cuyos resultados no son similares entre los programas: la duración del vídeo publicado varía mucho entre unas unidades y otras, desde los 3 minutos hasta los 23 minutos; el número de visitas que tiene cada contenido oscila entre las 200 visitas y las 1.000 visitas; y la respuesta del público también fluctúa, aunque en menor medida, en cuanto a las opciones que ofrece YouTube para que el usuario muestre su agrado o descontento con el contenido, estos datos revelan una ínfima participación por parte de los radiovidentes.

No existen contenidos radiovisados de programas completos porque la extensión del programa 'Hoy por Hoy', que dura 6 horas y 20 minutos, no lo permite y no sería un contenido fácil de gestionar ni práctico para el usuario. Es por este motivo que únicamente se publican contenidos de interés, entrevistas de actualidad y aquellas secciones populares entre los oyentes.

\subsection{Presentadores, invitados y COLABORAdORES}

En cuanto al análisis de presentadores, invitados y colaboradores no hay datos que indiquen que nos encontramos ante un programa radiovisado. Existen dos presentadoras, Pepa Bueno y Gemma Nierga, que se alternan durante el horario del programa; numerosos colaboradores permanentes, en este caso se ha analizado la colaboración de Manuel Jabois, e invitados motivados por la actualidad, como Cristina Cifuentes o Albert Rivera. Todos los participantes de los 4 programas radiovisados tendrían cabida en cualquier programa de radio tradicional, por lo que no se observan características ni contenidos propios o novedosos de la Radiovisión.

En todos los fragmentos de vídeos analizados se observa cómo los presentadores dan más importancia a lo que dicen que a lo que hacen: tienen más presente que están haciendo un programa de radio a que se les está grabando para emitir la entrevista de manera radiovisada. No sucede lo mismo con los entrevistados. Ellos tienen un fuerte conocimiento sobre comunicación no verbal debido a su profesión por lo que, incluso en radio o puede que porque sepan que les están grabando, intentan transmitir información también mediante sus movimientos corporales.

\subsection{Puesta en escena}

En el segundo apartado del análisis específico: «puesta en escena», comienzan a intuirse características comunes a todos los programas analizados que se pueden extrapolar a la tendencia generalizada en la Radiovisión actual.

En todas las unidades de análisis, los protagonistas aparecen sentados, siempre detrás de una mesa y ambos al mismo lado, lo que les permite establecer contacto visual con la cabina de realización situada en frente. De este modo solo se puede analizar su comunicación no verbal del tronco superior. La parte inferior del cuerpo permanece oculta en todos los vídeos. 
A la hora de visualizar el contenido a través de YouTube, todos los programas incluyen una cabecera corporativa al inicio y al final del vídeo. También aparece una mosca que se sitúa en la esquina superior derecha de la imagen con las palabras: 'Ser TV'.

Los programas comparten similitudes en cuanto al tipo de planos empleados: todos los vídeos usan planos fijos, es decir, no se emplea «zoom out» ni «zoom in» en ningún momento.

En aquellos programas que se han grabado con más de una cámara en el estudio se alternan planos generales y primeros planos. Únicamente se muestra algún plano lateral durante la entrevista de Albert Rivera, esta práctica ofrece al radiovidente una mayor apariencia de programa televisivo.

En el caso de la unidad de febrero, la presentadora, Pepa Bueno, apenas aparece en cámara a lo largo de la entrevista, ya que la imagen radiovisada se centra durante la mayor parte del tiempo en la invitada, Cristina Cifuentes.

Estos dos programas de contenido resumido, unidades de febrero y abril, emplean fundidos para realizar un salto de plano y de tiempo como consecuencia de ser un vídeo resumen de la entrevista completa.

Por su parte, las unidades de enero y marzo protagonizadas por Manuel Jabois y Thais Villas, presentan un contenido íntegro y solo disponen de una cámara, por lo que no se cambia de plano en ningún momento.

Si se presta atención a los cambios de planos, se puede determinar el número de cámaras empleadas para cada grabación, muy reducido si se compara con cualquier programa de televisión. Normalmente se utiliza solo una cámara. Si el entrevistado es relevante se emplean dos o incluso tres. Sin embargo, en algunos vídeos la imagen tiembla debido a que el soporte de la cámara no está bien fijado. Esto indica que la imagen no se cuida en especial, pese a ser la novedad principal que introduce la Radiovisión.

Además, en ninguna de las unidades analizadas se ha observado el uso de colchones musicales o música de ningún tipo como elementos radiovisados.

Pese a estas semejanzas, los programas radiovisados analizados ofrecen también muchas diferencias entre sí, hecho que dificulta la identificación del espacio radiovisado por parte del radiovidente.

El estudio de radio o plató de Radiovisión en el que se graba el programa no es siempre el mismo. Dos de las entrevistas, probablemente las consideradas por la emisora como más relevantes por ser protagonizadas por dos líderes políticos, se llevan a cabo en un estudio corporativo con los logos oficiales de 'Hoy por Hoy'. No sucede lo mismo con el programa de enero de Manuel Jabois, grabado en un estudio de 'Cadena Ser', sin referencias a 'Hoy por Hoy'; o el protagonizado por Thais Villas, que tiene lugar en una sala de estudio con fondo neutro en la que la única referencia a una emisora nacional son los logos de los micrófonos. Esta circunstancia dificulta que el radiovidente identifique un programa con sus colores corporativos o con su estudio de grabación particular, como sí ocurre en televisión donde un programa se graba siempre en el mismo plató.

Tampoco hay público en ninguno de los programas radiovisados o, al menos, no se les enfoca ni aparecen en pantalla.

La puesta en escena solo se cuida en uno de los cuatro programas analizados. Durante la entrevista a Albert Rivera el estudio está ordenado y existen logos corporativos que indican al radiovidente el programa y la cadena que está realizando la entrevista. Albert Rivera es un líder político de actualidad y la emisora sabe que el vídeo será popular, motivo por el cual el escenario se cuida.

Sin embargo, en los otros tres programas la puesta en escena obvia por completo que se está grabando la entrevista: abrigos en los respaldos de las sillas, botellas y alimentos sobre la mesa, diferentes 
y numerosos aparatos electrónicos que dificultan la visualización de los protagonistas y guiones de papel esparcidos por el escritorio, muestran una escena desaliñada que nunca veríamos en televisión.

Al observar la puesta en escena en la unidad de análisis de enero, nada indica quién es el presentador y quién el colaborador. En el resto de programas tampoco se distingue de manera evidente quién ocupa la función de dirigir el programa si no se conoce a sus protagonistas. Esta situación puede despistar a un radiovidente que consume contenidos radiovisados de 'Hoy por Hoy' por primera vez y desconoce a sus profesionales. Además, es una circunstancia que no se observa en televisión, donde el presentador siempre tiene una posición privilegiada que indica a la audiencia su condición de conductor del programa.

Otro parámetro que llama la atención es la iluminación de la escena, aspecto fundamental en cualquier programa de televisión. La iluminación en las unidades radiovisadas analizadas solo se cuida en las entrevistas relevantes, las de los líderes políticos. En la colaboración de enero de Manuel Jabois, la luz es muy tenue y débil, como si indicase la temprana hora del día a la que se está grabando la emisión. Por su parte, en el programa de marzo la iluminación no se cuida en absoluto. Gemma Nierga y Thais Villas están iluminadas con una lámpara corriente y es complicado distinguir el resto del estudio que permanece prácticamente a oscuras.

Un elemento novedoso para la radio es el uso de rótulos, la Radiovisión sí lo permite. Sin embargo, los rótulos no se emplean en todos los contenidos radiovisados. De los cuatro programas analizados solo dos incluyen los nombres y profesión de los entrevistados o colaboradores al inicio de la grabación. Este aspecto muestra una desigualdad evidente en la edición de los vídeos. No hay criterios establecidos para que todos los programas radiovisados tengan un presencia similar que les identifique como contenidos de 'Hoy por Hoy'.

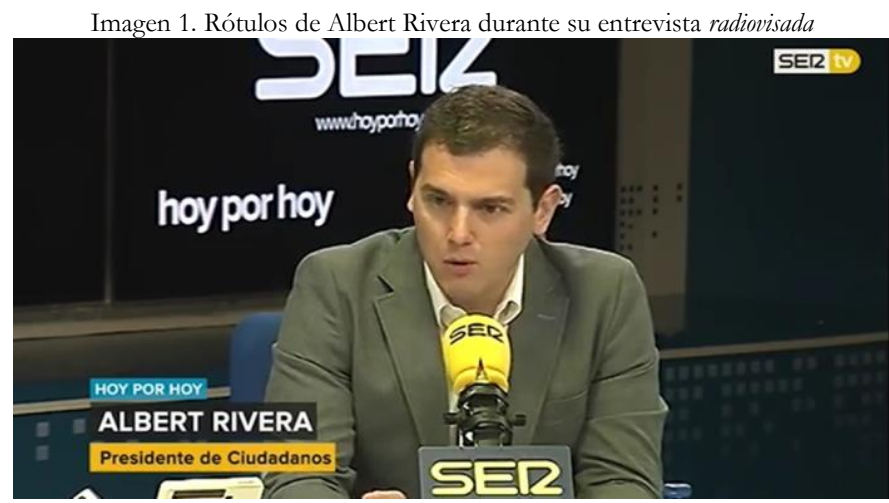

Fuente: canal de Cadena SER en YouTube.

\subsection{ConTENidos}

El tercer apartado del análisis específico ha permitido recabar información sobre los contenidos emitidos en este nuevo modelo radiovisivo.

En esta investigación se han analizado tres entrevistas y una colaboración de opinión. La elección de las unidades ha sido aleatoria, pero las entrevistas y las colaboraciones son los contenidos predominantes en la lista de reproducción de 'Hoy por Hoy' en el canal de 'Cadena Ser' en YouTube.

Los temas principales tratados en los programas analizados: biografía, política y actualidad son habituales en la radio tradicional. No se ha observado ningún contenido novedoso por el hecho de que el programa se estuviese grabando en vídeo.

Según el programa, se emplean: sintonías, indicativos, paso a, audios pregrabados... por lo que se usan elementos de continuidad habituales en la radio tradicional. No se añade ningún elemento sonoro 
novedoso y, en los programas de contenidos resumidos, se incluyen los fundidos como elemento de continuidad visual.

También la publicidad en el nuevo modelo radiovisivo se emite del mismo modo que en la radio tradicional. No se muestra ningún producto comercial, sino que se publicita mediante recursos sonoros, por ejemplo: publicitar un disco de música mediante la emisión de fragmentos musicales del mismo. Alguna unidad de análisis incluye autopromociones del propio programa 'Hoy por Hoy'.

En cuanto a las apelaciones a redes sociales y aplicaciones solo se observan en el programa de enero con Manuel Jabois. Al ser la Radiovisión un modelo posible gracias a Internet y aliado de las nuevas tecnologías, sorprende que las innovaciones tecnológicas no sean apenas mencionadas en sus programas.

Las apelaciones a los oyentes y espectadores también aparecen a lo largo de los vídeos, pero del mismo modo que en cualquier programa de radio tradicional.

\subsection{COMUNICACIÓN NO VERBAL EN RADIOVISIÓN}

En el último apartado del análisis se ha observado la comunicación no verbal de los protagonistas de los programas. Comenzaremos por los resultados obtenidos tras observar la kinesia de presentadores, colaboradores e invitados.

\subsubsection{KINESIA}

La postura adquiere, con el modelo radiovisivo que permite la cuarta pantalla, una importancia insólita en la radio tradicional. En televisión es visible una postura abierta entre interlocutores, mientras que en la Radiovisión los micrófonos radiofónicos provocan que los interlocutores ofrezcan una postura más cerrada. Los micrófonos característicos de la radio se sitúan encima de la mesa y los interlocutores deben dirigirse hacia ellos para que el sonido se emita de forma correcta. Esta postura tan exigente provoca que se descuide la forma en la que se dirigen hacia el resto de participantes y que la orientación de los cuerpos sea menos directa.

A la posición de los micrófonos radiofónicos se suman los papeles que contienen el guion del programa que suelen estar situados encima de la mesa. Esta circunstancia afecta a los movimientos de cabeza de los protagonistas que se debaten entre mirar al frente, para favorecer el sonido de su voz; mirar hacia abajo, para leer el guion; o mirar lateralmente hacia donde se encuentra su interlocutor. Esta problemática afecta por igual al movimiento de los hombros y los troncos. Concretamente, en la unidad de abril se observa cómo Gemma Nierga se inclina sobre la mesa ofreciendo una postura que no se vería nunca en un plató de televisión.

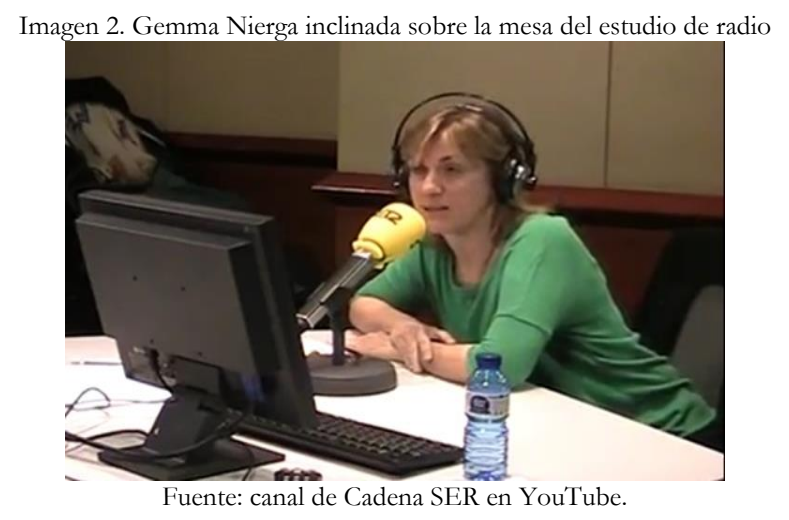


Apenas existen gestos reguladores, utilizados para sincronizar, regular y ayudar a la interacción comunicativa, esto es debido al uso de un guion previamente escrito. Sin embargo, la ausencia de reguladores provoca que en ocasiones los interlocutores se interrumpan unos a otros, esta situación se observa en la unidad de marzo. Su uso ayudaría a establecer una comunicación más ordenada y comprensible para el radiovidente.

Los gestos emotivos dependen de la comunicación interpersonal que tiene cada interlocutor, por lo que no se aprecian gestos destacables por tratarse del modelo radiovisivo. Sí se observa, sin embargo, cómo los invitados que trabajan o aparecen en televisión son más expresivos que las presentadoras o colaboradores de radio.

A la hora de hablar de los gestos adaptadores, gestos inconscientes que reflejan emociones que no se quieren expresar, hay que destacar a Pepa Bueno. La presentadora realiza muchos de estos gestos inconscientemente. En el programa de enero se puede observar cómo se retuerce el pelo con los dedos de la mano, como si intentase flirtear con su interlocutor, que en esa ocasión es Manuel Jabois; este gesto también puede reflejar un alto grado de inseguridad. En la unidad de febrero, Pepa Bueno hace una pregunta a Cristina Cifuentes mientras se observa las uñas de modo femenino.

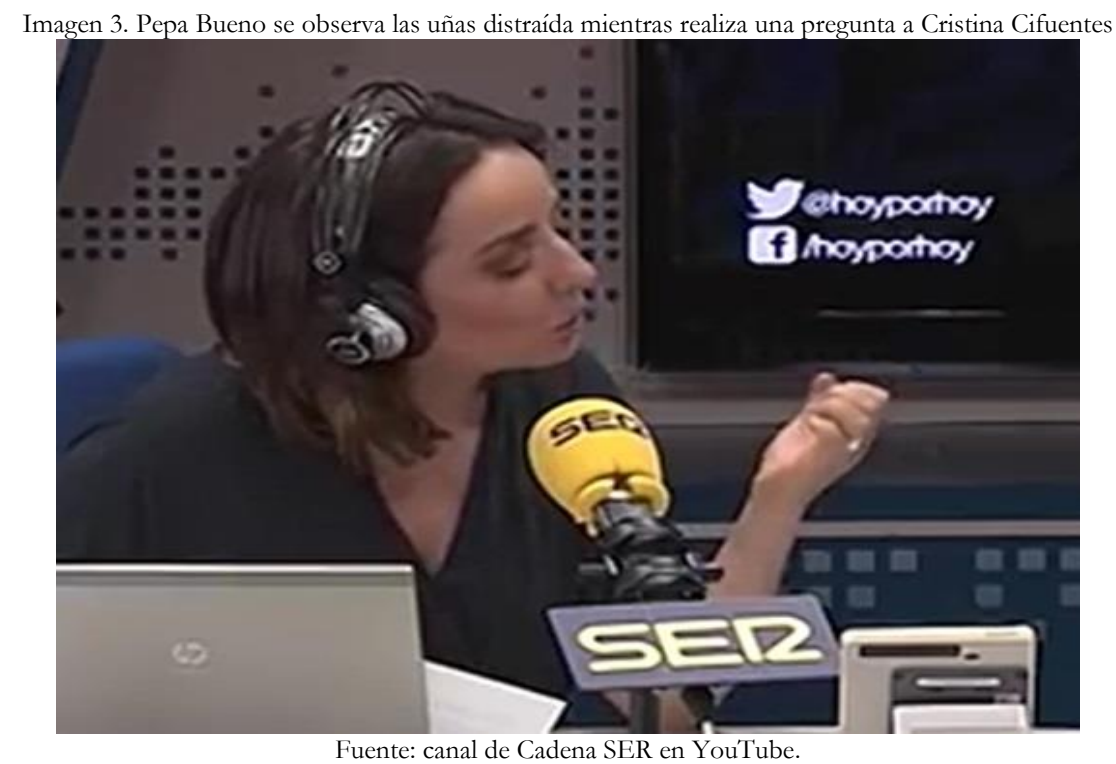

La presentadora también suele morderse el labio a menudo mientras escucha a sus interlocutores, este gesto se suele interpretar como muestra de timidez, titubeo o indecisión. Muchos gestos que indican que la presentadora está confiada en el estudio de radio y que el hecho de que la escena se esté grabando en vídeo no la influye hasta el punto de intentar controlar su lenguaje no verbal.

En el caso de la entrevista de Albert Rivera, el líder político de manera inconsciente levanta con frecuencia la ceja derecha cuando está esperando la pregunta; arruga la frente, gesto que indica reflexión y concentración; o se toca la nariz cuando le disgusta que le interrumpan mientras habla.

Que el presentador haga gestos a la sala de control para comunicarse es algo muy común en radio y que se evita en las emisiones de televisión. Este tipo de comportamientos se ve claramente en la unidad de marzo, cuando Gemma Nierga se comunica con los realizadores mediante ademanes y aspavientos muy expresivos con los brazos y las manos. Esta situación es difícil de ver en televisión si no es por un error de la emisión en directo. 


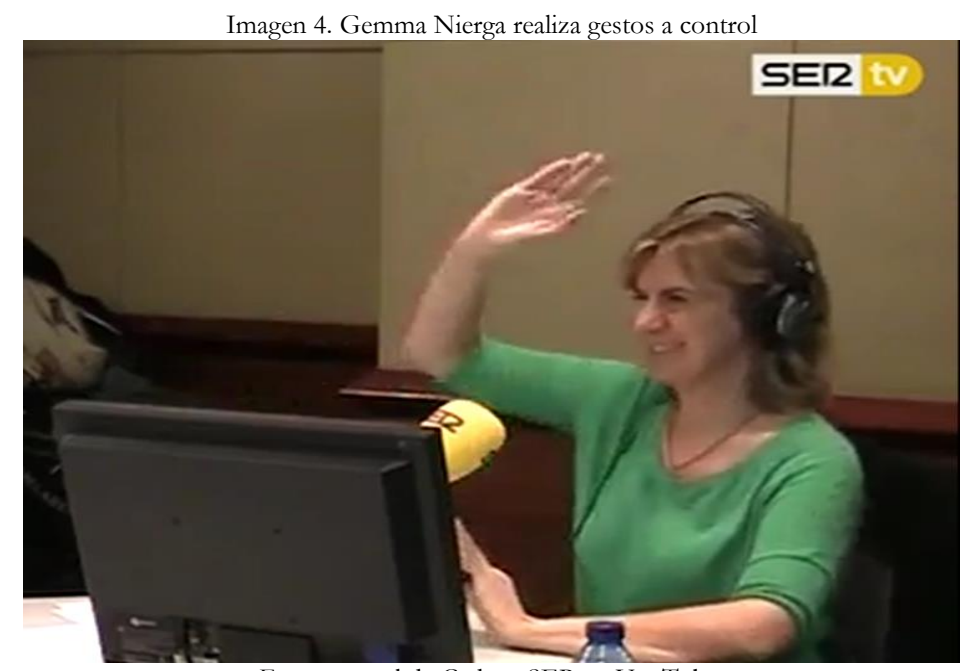

Fuente: canal de Cadena SER en YouTube.

La mirada permite observar diferencias entre la radio y la televisión que afectan a la Radiovisión. En los programas analizados, los protagonistas nunca miran a cámara, gesto que sí se hace en televisión. Los presentadores tampoco miran siempre al interlocutor, ya que en radio se puede aprovechar que el invitado está contestando para mirar rápidamente el guion. De hecho, en el momento que surgen preguntas espontáneas no incluidas en el guion es cuando el locutor mira al entrevistado. En televisión los presentadores suelen evitar tener que mirar papeles y permanecen más atentos a las respuestas de su interpelado.

En otros casos, la mirada ni siquiera se levanta de los papeles que contienen el guion del programa, es el caso de Manuel Jabois que lee todo lo que dice.

El turno de palabra lo marca el guion, lo que provoca la ausencia de gestos reguladores en la interacción de los protagonistas con alguna consecuencia negativa para la claridad del diálogo. Según las características propias de la entrevista y del entrevistado, el registro del lenguaje varía entre formal, para los contenidos políticos; e informal, los contenidos biográficos, del mismo modo que se aprecia en televisión o en cualquier ámbito social.

\subsubsection{ProxémicA}

Los datos recogidos en base a la proxémica de los vídeos indican que en todas las unidades analizadas se emplea la distancia social, determinada por la distribución y anchura de los estudios de radio. Esto significa que los interlocutores se sitúan a una distancia de entre 120 y 360 centímetros. Esta distancia no varía porque los protagonistas permanecen sentados delante de sus micrófonos durante todo el programa.

Los platós de televisión son más grandes y por ello se usa la distancia pública, mayor de 360 centímetros. El objetivo tanto en Radiovisión como en televisión es rellenar el espacio que aparece en la imagen en pantalla.

La distribución del espacio en todos los vídeos es similar porque los estudios de radio también lo son. Los estudios de radio analizados en 'Hoy por Hoy' son similares pero no iguales, lo que no ayuda a que el radio-espectador relacione un espacio concreto con un programa determinado, como sí sucede en televisión. 


\subsubsection{INDUMENTARIA}

Respecto a la indumentaria destaca el uso de los cascos. Todos los sujetos analizados llevaban cascos excepto los líderes políticos, no se puede determinar si por una cuestión de apariencia con motivo del modelo radiovisado.

La ropa es adecuada para realizar una grabación de la entrevista. La vestimenta está cuidada y es formal en las entrevistas con políticos y se descuida en entrevistas como la de Thais Villas, donde destaca un estilo informal. En televisión las personas suelen evitar el uso de complementos, en los contenidos radiovisados analizados se observan ciertos complementos como pendientes, relojes o anillos, pero nada que llame la atención con respecto a lo que se suele ver en televisión.

Tras esta exposición de resultados ya podemos realizar una enumeración de conclusiones extraídas a partir de este estudio que nos ayudarán a responder a las hipótesis iniciales.

\section{CONCLUSIONES}

Después de haber analizado las cuatro unidades de Radiovisión seleccionadas según la metodología expuesta y de haber extraído los resultados del análisis, se pueden enunciar conclusiones que permiten esbozar la situación actual de la Radiovisión a través de la cuarta pantalla:

a) La Radiovisión no imita a los programas de televisión. Existen numerosas diferencias entre ambos modelos tal y como se ha explicado en los resultados.

Sin embargo, no imitar a la televisión no tiene por qué significar que la Radiovisión tenga errores que deba subsanar para acercarse al modelo televisivo. Estas diferencias se pueden entender como un nuevo estilo propio que ha sido creado por y para la Radiovisión emitida por tecnología móvil.

b) A lo largo de la investigación se han descrito numerosos elementos que demuestran cómo se descuida la puesta en escena en los programas radiovisados. Además, este aspecto se cuida en mayor o menor medida según la importancia y popularidad del entrevistado, lo que evidencia que la Radiovisión no trata por igual todos los contenidos. Respecto a la comunicación no verbal, la Radiovisión aportará un nuevo perfil profesional al periodismo. Se ha observado que los presentadores y colaboradores de radio prestan más atención a lo que dicen que a lo que hacen, por lo que en la actualidad se descuida la comunicación no verbal en la Radiovisión. Con este nuevo modelo surge la necesidad de crear un perfil profesional radiofónico que cuide su lenguaje no verbal en pantalla. Un desafío para el periodista tradicional y una oportunidad de futuro para las nuevas generaciones de profesionales de la comunicación.

c) La radio ha comenzado su proceso de aleación con Internet, pero únicamente en el ámbito tecnológico al emitir imagen a través de la cuarta pantalla. Muchos autores sitúan los contenidos radiofónicos en el núcleo de la reconversión que debe sufrir el medio para adaptarse a la nueva sociedad emergente. En este estudio se ha demostrado el anquilosamiento de los contenidos radiovisados, su poca innovación y su evidente carácter tradicional. La Radiovisión actual carece de fórmulas innovadoras, elementos novedosos, contenidos originales y una programación basada en las preferencias de sus usuarios. Además, se han observado ínfimas apelaciones a las redes sociales o a la participación de los oyentes en el radio. Esta característica de la Radiovisión contrasta con la aparición del usuario 'prosumer', dispuesto a participar activamente en la difusión y creación de contenidos radiofónicos y radiovisados. Todo ello indica que la definición de Radiovisión de Gorka Palazio que incluye «hiperenlaces, datos, ciber-revistas, imágenes (fotos, gráficos y esquemas), vídeo (ilustraciones, animaciones y vídeo real) e informes multimedia» otorga características y funciones prescindibles para este nuevo modelo de radio a través del teléfono móvil. 
d) Los programas de Radiovisión se publican en la página web de la emisora y en la plataforma virtual de YouTube. Por el momento, estos contenidos no se pueden consultar en ningún otro sitio web. También se ha observado que la plataforma virtual ofrece mayores facilidades al usuario para acceder a vídeos concretos. La página web de la emisora no permite encontrar los contenidos de manera directa y sencilla, lo que dificulta que los usuarios accedan al modelo de Radiovisión a través de su móvil. Actualmente, en la sociedad de la información hay una gran participación activa de usuarios a través de las redes sociales, sin embargo, esto no se observa en los canales empleados por la Radiovisón, donde la implicación de los usuarios es mínima. Además, con este nuevo modelo radiofónico, el tradicional transistor queda obsoleto como canal de difusión en favor de la cuarta pantalla.

e) Existe desigualdad en la edición y formato de los contenidos radiovisados. La no homogeneización del producto radiovisado dificulta que el usuario identifique el programa.

f) Actualmente no se emite Radiovisión en directo. Sin embargo, la tecnología actual sí lo permitiría y en la sociedad de Internet los usuarios demandan constantemente información actualizada e inmediata. El hecho de que una emisora publique los vídeos de sus programas posteriormente a su emisión provoca una obsolescencia informativa que se traduce en una pérdida de interés por parte del usuario.

g) La Radiovisión no ha provocado que se modifique la estética tradicional del estudio de radio. Mantener la apariencia del medio «que no se ve» y no prestar atención a la imagen que se ofrece provoca una pérdida de protagonismo de la Radiovisión que dificulta que este nuevo modelo de radio evolucione.

h) Existen dos tipos de contenidos radiovisados: contenidos íntegros y contenidos resumidos. Los contenidos íntegros ofrecen al usuario el vídeo del programa sin cortes ni ediciones. Por su parte, los contenidos resumidos incluyen los fragmentos más relevantes del programa según la cadena radiofónica. Estos vídeos sí están editados y permiten que el usuario se haga una idea de lo que ha sido el programa completo sin tener que visionarlo entero.

Tras todo lo expuesto, cabe concluir que hay aspectos que la radio a través de la cuarta pantalla debe comenzar a cuidar. Uno de los más importantes son los contenidos y la programación. Modificar la oferta en base a las preferencias de los usuarios y permitir que también ellos generen sus propios contenidos aumentará el interés de una audiencia con herramientas de participación insólitas e innovadoras. La radio tendrá que modificar su apariencia para mostrarse ante una sociedad que demanda información multimedia, posible gracias la tecnología móvil, y en la que la comunicación no verbal es fundamental para ofrecer un mensaje completo, especialmente en el ámbito político. Sea o no la Radiovisión el resultado final de la inevitable revolución que va a sufrir este medio tradicional, lo que está claro es que, como aconsejaría el empresario de éxito y escritor Jack Welch, la radio debe cambiar antes de que tenga que hacerlo.

Sin renunciar a esa «comunicación silenciosa entre locutor y oyente» que conquistó a Marshall McLuhan, la radio deberá crear una nueva entre telelocutor y radiovidente capaz de seducir a la audiencia a través de la cuarta pantalla. 


\section{BIBLIOGRAFÍA}

AIMC (2012). Radio Tradicional vs. Radio Online (Radio On Off), marzo-2012. Recuperado de: http://www.aimc.es/-La-Radio-Tradicional-vs-Online,196-.html

AIMC (2016). Estudio General de Resultados (EGM). Año móvil octubre-2015, mayo-2016. Recuperado de: http://www.aimc.es/Entrega-de-resultados-EGM-2\%C2\%AA-ola,1823.html

AIMC (2016). Resumen General del EGM. Abril-2015 a marzo-2016. Recuperado de http://www.aimc.es/Entrega-de-resultados-EGM-1\%C2\%AA-ola, 1254.html

AIMC (2016). Audiencia de Internet. Febrero-marzo 2016. Recuperado de: http://www.aimc.es/Entrega-de-resultados-EGM-1\%C2\%AA-ola,1768.html

Calvo, E., \& Padilla, G. (2011). Radio 3.0. Éxito durmiente. En López, N., y Ortiz, M. A. (Eds.), Radio 3.0: una nueva radio para una nueva era (pp. 281-300). Madrid: Fragua.

Centro de investigaciones sociológicas (2013). Informe CIS. Barómetro marzo 2013. (Informe Núm. 2981). Recuperado de http://www.cis.es/cis/export/sites/default/Archivos/Marginales/2980 2999/2981/Es2981.pdf

Centro de investigaciones sociológicas (2016). Informe CIS. Barómetro febrero 2016. (Informe Núm. 3128).

Recuperado

de:

http://www.cis.es/cis/opencm/ES/1 encuestas/estudios/ver.jsp?estudio $=14263$

Centro de investigaciones sociológicas (2016). Informe CIS. Barómetro marzo 2016. (Informe Núm. 3131).

Recuperado

http://www.cis.es/cis/opencm/ES/1 encuestas/estudios/ver.jsp?estudio=14272

Cebrián, M. (2009). Expansión de la ciberradio. En Enlace Revista Venezolana de Información, Tecnología y Conocimiento, 6(1), 11-23.

https://dialnet.unirioja.es/servlet/articulo?codigo $=2932188$

Cebrián, M. (2011). La radio en el entorno de las multiplataformas de comunicaciones. Recuperado de: https://blogintercomradio.files.wordpress.com/2011/09/la-radio-en-el-entorno-de-lasmultiplataformas-de-comunicaciones.pdf

González, M. J. (2010). La ciberradio. Nueva alternativa de futuro para la radio. Madrid: CEU San Pablo. Recuperado de http://www.injuve.es/sites/default/files/RJ88-05.pdf

González, M. J. (2008). La radio entre la información y el entretenimiento: Radio 10 y Cadena SER. Revista de la SEECI, 15, 40-58. (pp. 40-58). Recuperado de: http://www.ucm.es/info/seeci/Numeros/Numero 15/InicioN15.html

Gutiérrez, M., Ribes, X., \& Monclús, B. (2011). La audiencia juvenil y el acceso a la radio musical de antena convencional a través de internet. Revista Comunicación y Sociedad, 24(2), 305-311. Recuperado de: https://dialnet.unirioja.es/servlet/articulo?codigo $=3817193$

Gutiérrez, M., Ribes, X., \& Monclús, B. (2015). Del oyente al radio prosumer: gestión de la participación de la audiencia en la radio del siglo XXI. Trípodos, 36, 55-74. Recuperado de: https://dialnet.unirioja.es/servlet/articulo?codigo $=5260937$

Huertas, A., \& Figueras, M. (Eds.) (2014). Audiencias juveniles y cultura digital. Barcelona: Bellaterra, Institut de la Comunicació, Universitat Autonoma de Barcelona.

López, N. (2011). La radio se transforma: nuevas tecnologías, nuevos hábitos de consumo y nuevos perfiles para el medio más cercano. En N. López \& M. A. Ortiz (Eds.), Radio 3.0: una nueva radio para una nueva era (pp. 15-40). Madrid: Fragua.

López, N., Gómez, L., \& Redondo, M. (2014). La radio de las nuevas generaciones de jóvenes españoles: hacia un consumo on line de música y entretenimiento. Revista Zer, 19-37, 45-64.

López, N., \& Gómez, L. (2014). Nuevos hábitos de los jóvenes españoles y tendencias de futuro en el consumo de radio y televisión. Revista de Historia y Comunicación Social, 19 (núm. esp. febrero), 327340).

López, N., \& Gómez, L. (2014). La democratización del proceso comunicativo en radio: los jóvenes prosumidores. Revista de Comunicación Vivat Academia, año XVII, núm. 126, marzo, 31-53. 
López, N., \& Gómez, L. (2014). Claves de la desafección juvenil hacia la radio generalista española. En Revistas Latinas, VI Congreso Internacional Latina de Comunicación Social, Universidad de la Laguna, diciembre. Recuperado de: http://www.revistalatinacs.org/14SLCS/2014 actas/022 Lopez.pdf

López, N., \& Gómez, L. (2015). El magazine radiofónico: La evolución de un formato híbrido de éxito en las cadenas generalistas. Revista Ámbitos, 30. Recuperado de: http://ambitoscomunicacion.com/2015/el-magazine-radiofonico-la-evolucion-de-un-formatohibrido-de-exito-en-las-cadenas-generalistas/

Pacheco, M. A. (2009). La estructura actual de las retransmisiones futbolísticas en los programas de radio en España. Revista Ámbitos, 18, 99-114. Recuperado de: https://dialnet.unirioja.es/servlet/articulo?codigo $=3154788$

Palazio, G. J. (1999). La radiovisión, el nuevo medio multiservicio. Zer: Revista de estudios de comunicación, 6. Recuperado de: http://www.ehu.eus/zer/hemeroteca/pdfs/zer06-09-palazio.pdf

Peinado, F. (Coord.) (2015). Formación, perfil profesional y consumo de medios de alumnos en Comunicación. Cuadernos Artesanos de Comunicación, 77.

Ribes, F. X. (2003). Internet: la radio que se ve. En N. López \& C. Peñafiel (Eds.), Odisea 21. La evolución del sector audiovisual (pp. 89-102). Madrid: Univ. Francisco de Vitoria.

Rodríguez, D., \& Peinado, F. (2011). Nuevos modelos de negocio para la radio. En López, N., \& Ortiz, M. A. (Eds), Radio 3.0: una nueva radio para una nueva era (pp. 140-160). Madrid: Fragua.

Rodríguez, L. (Director del Área de Voz y Datos de Retevisión) en la conferencia: La radio en Internet. En el seminario titulado: La radio ante la era digital: la segunda revolución (UIMP, Santander). 26 de junio de 1997. En Palazio, G. J (1999). La radiovisión: el nuevo medio multiservicio.

Salaverría, R. (Profesor de la Universidad de Navarra e Investigador de medios digitales) en la conferencia: El periodismo en el internet de las cosas. Universidad de Valladolid, Valladolid, 11 de mayo de 2016.

Soengas, X. (2013). Retos de la radio en los escenarios de convergencia digital. AdComunica, 5. doi: http://dx.doi.org/10.6035/2174-0992.2013.5.3

Ventero, M., \& Peña, P. (2011). Nuevas formas de participación en Radio. Radio tradicional y redes sociales. En N. López \& M. A. Ortiz (Eds.), Radio 3.0: una nueva radio para una nueva era (pp. 231248). Madrid: Fragua. 